\title{
Defining the architectural characteristics of multi-purpose shelters: drawing issues through analysis of disaster shelters
}

\author{
B. Shong \\ Department of Architectural Design, Hanbat National University, Korea
}

\begin{abstract}
This study was initiated to draw the necessary issues required for drafting the architectural guidelines and programs for constructing multipurpose shelters, and analyzes several cases of disaster shelters to survey the perspectives of the requiring party and the proposing party. It analyzes three different types of disaster shelters, draws keywords, and categories them into eight issues through the panel survey. In conclusion, this paper selects the following as the essential factors of disaster shelters: functional, economic, sustainable, safe, comfortable, social, healing, and aesthetic. 'Functional' means that the shelter should not only be able to provide a safe environment that protects its residents from wind, cold, heat, earthquakes, or water, but also be designed in a way that even the nontrained are able to build it quickly and easily. 'Economic' refers to production costs and also providing options of easily acquirable ingredients. 'Sustainable' speaks of both recycling the shelter as a whole, and also processing its deconstructed remnants in an ecofriendly manner. As the shelter structure itself being safe the obvious premise, 'safe' requires the shelter to be a space that is safe from crime and also a space that provides psychological safety. 'Comfortable' was selected as an essential element in regards to the necessities of housing. 'Social' refers to the social, cultural, and religious requirements of a shelter. 'Healing' was chosen because there is a need for study in regards to the shelter environment serving as a means of healing the psychological anxiety and wounds, given that the shelter sits within a catastrophe. 'Aesthetic' seeks to link the image or sentiment presented by the form to the human aesthetic instinct, leading the influence of recognition and healing to be discovered within the environment that the shelter is place in.
\end{abstract}

Keywords: emergency shelter, multi-purpose shelter, planning criteria, architectural guideline, shelter competition, environmental art. 


\section{Introduction}

Since humans started living on the earth the role of architecture has been a bowl used to hold human life. Leaving considerations of artistic aspect aside, the basic function of architecture is still protecting humans from cold and hot, and providing refuge for people. Supplying adequate housing is a sublime mission of architecture in frequent disastrous situation from climate changes and human error accidents.

Flood, landslide, earthquake, tsunami and war have seriously threatened local residents' lives from that time on. Recently, the minimum housing conditions with the appropriate technologies come to the forefront as necessary requisites for living a normal life in a sudden catastrophe. Japanese architect Shigeru Ban has built Paper Log houses in response to the Rwanda refugee crisis in 1994. Ferrara Design Inc. has offered 700 low-cost temporary emergency shelters, Global Village Shelters, to Grenada damaged by the hurricane in 2004. A total of 62,000 temporary houses have been built after the tsunami of 2011 .

The utility of shelters is not limited to disaster aspect. The nomadic feature of modern life more and more expanding and the situational conditions frequently occurring in urban space call for the shelters excellent in installation and displacement. The shelter become not only commercial facilities like kiosk, food truck and coffee truck, but also objects of artistic presentation like the Home Delivery Exhibition of MOMA.

Paying attention to the various applicability of shelter this study aims to give direction to draw up programs and guidelines for multi-purpose shelter. The case analysis for the different types of disaster shelters will deduce helpful issues for setting up programs and guidelines. The issues will be set priorities and importance through a later panel survey.

Three cases represent the different types of disaster shelters. A 'Shelter Competition' by John Brown University represents the idea competition for undergraduate students including practical conditions such as structural and functional problems. 'Emergency shelter exhibition' as an invited completion for architects shows the ideas and characteristics of their author rather than technical aspects. 'Red Dot Design Award' appeals to how we assess the design oriented idea focused on the creativity.

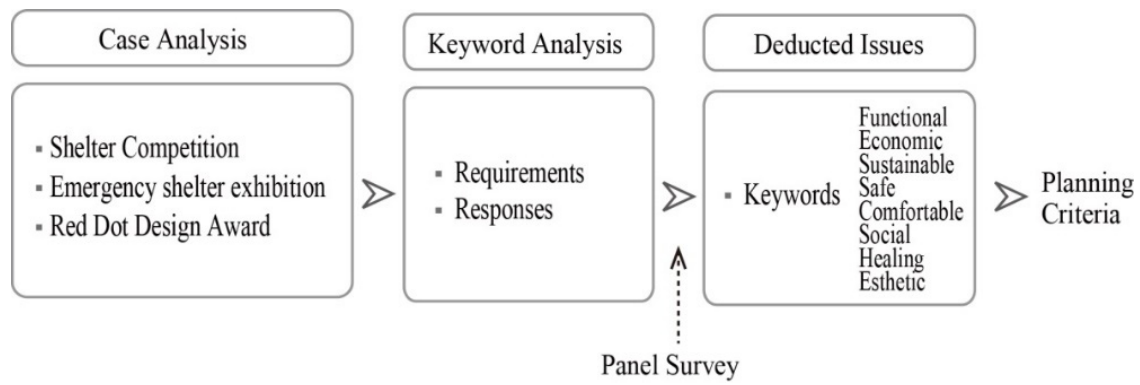

Figure 1: Research process. 


\section{Analyses of disaster shelter}

\subsection{Shelter competition}

John Brown University with Samaritan's Purse has managed the 'Shelter Competition' for American students since 2012. Considering of all phases of disaster response - the initial phase which requires 'emergency' shelters, the second phase which requires 'transitional' shelters (1-3 years), and the final phase which requires permanent shelters - participants are invited to design and build a prototype of a disaster shelter for rapid deployment and set-up. For the 2015-2016 competition, a specific scenario of the refugee crisis in the Middle East and Eastern Europe was selected to allow teams to focus on a specific disaster type and location as well as cultural considerations.

The shelter should accommodate a family of 4 with a minimum allocation of 3.5 square meters of space per person with adequate flexibility to respond to social, cultural and religious requirements. It has to provide protection from extremely hot summers, and cold and rainy winters performing well structurally against wind and seismic loads. Economy of scale during the production phase should be considered as vitally important like cost-effective is $\$ 1500$ or less to fabricate. Overall weight should be no more than $200 \mathrm{~kg}$ per package to allow handling without equipment [1].

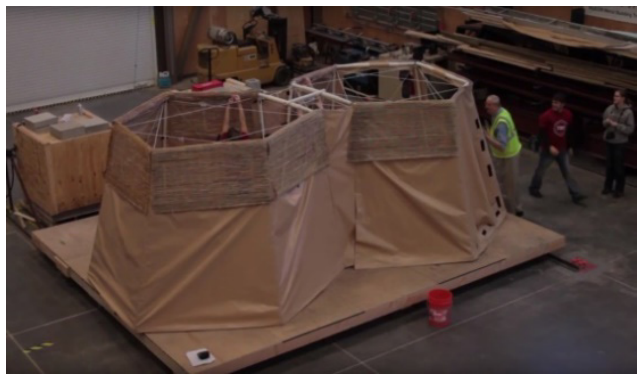

Figure 2: Setting up a disaster shelter of 2013 participant.

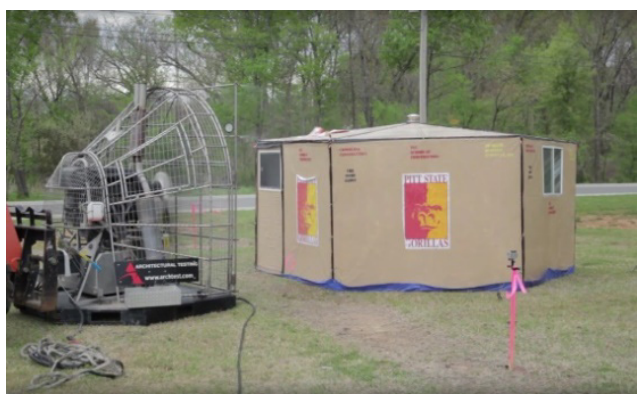

Figure 3: Wind loads testing of a participant. 
Even if it was limited only for domestic students - so, there weren't many participants - 'Shelter Competition' means a lot. There were many specific conditions which would be planning criteria for disaster shelters like standards, accommodation requirements, physical performance, materiality, costeffectiveness, packaging and transport.

\subsection{Emergency Shelter Exhibition}

Motivated by Tohoku Great Earthquake in 2011, some international architects have created an exhibition highlighting the need for emergency shelters in disaster zones and bringing awareness to the public about the role of the design and construction industry in the aftermath of natural disasters. This exhibition was to propose shelters that could not only protect people from rain and other elements in emergency situations but also provide a space to feel secure and comfortable in a disastrous environment, which is fundamental to the recovery process [2]. The exhibitions were held annually in Sydney 2011, in Brisbane 2012 and in Melbourne 2013.

Analyzing the shelters presented by participants we notice that the architects have more concentrated on their personal tendency than functional requirements. In case of LAVA exhibited in Sydney 2011, the shelter is a concept for an inhabited molecule. Based on a water-molecule, it references the Japanese Metabolist movement's idea of prefabricated capsules as living space. The base molecule is shipped as a flat pack and the interior carved out of locally available materials [3].

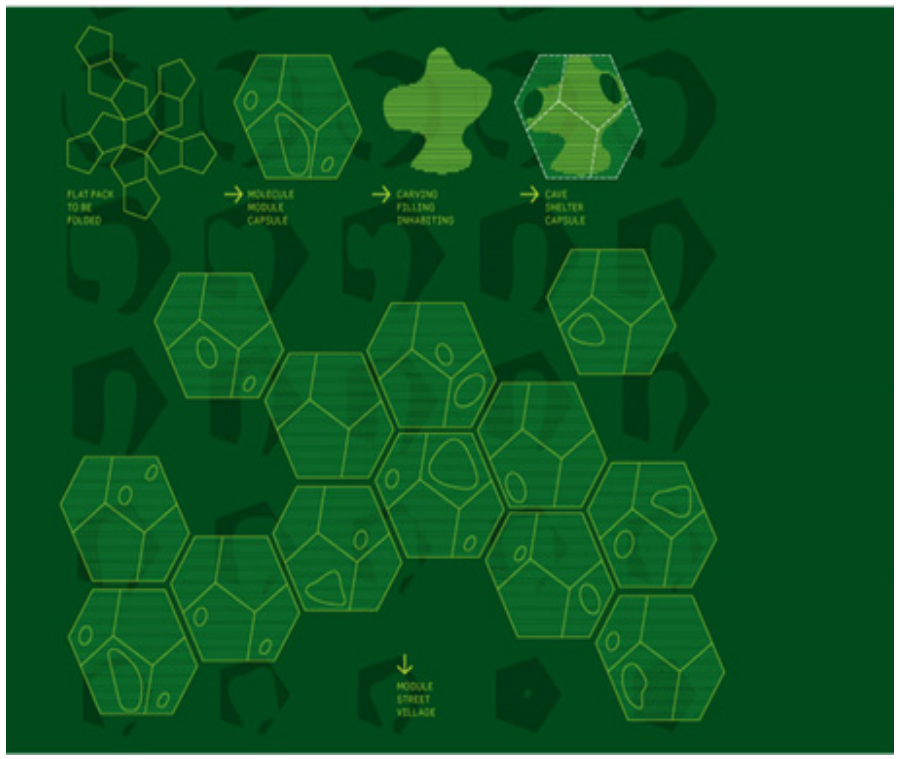

Figure 4: Planar figure of Digital Origami. 


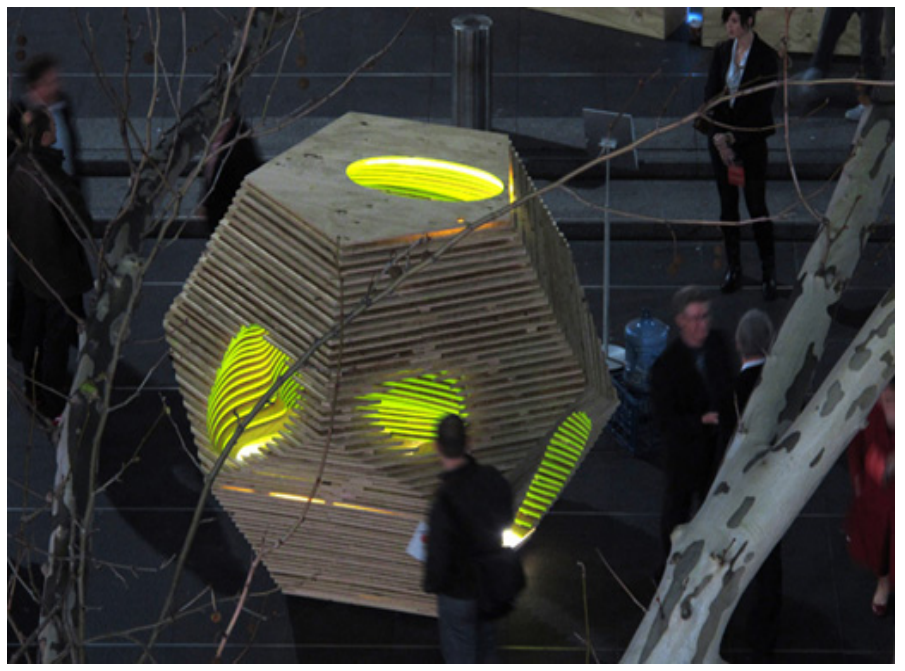

Figure 5: Installed Digital Origami in site.

COX presented in Melbourne 2013 proposed the methods of assembly as a pre-fabricated flat pack delivered to a disaster area or constructed on site with any flat, manually deformable material found in debris. The simple form is derived by drawing the ends of a sheet of cardboard or similar into a u-shape to form a 3 -sided enclosure, to complete the shelter a single roof/wall piece is gently rolled over to intersect with the u-shaped walls [4]. COX presents the reuse of versatile materials, the simple form universally understandable and the restoration of a sense of community.
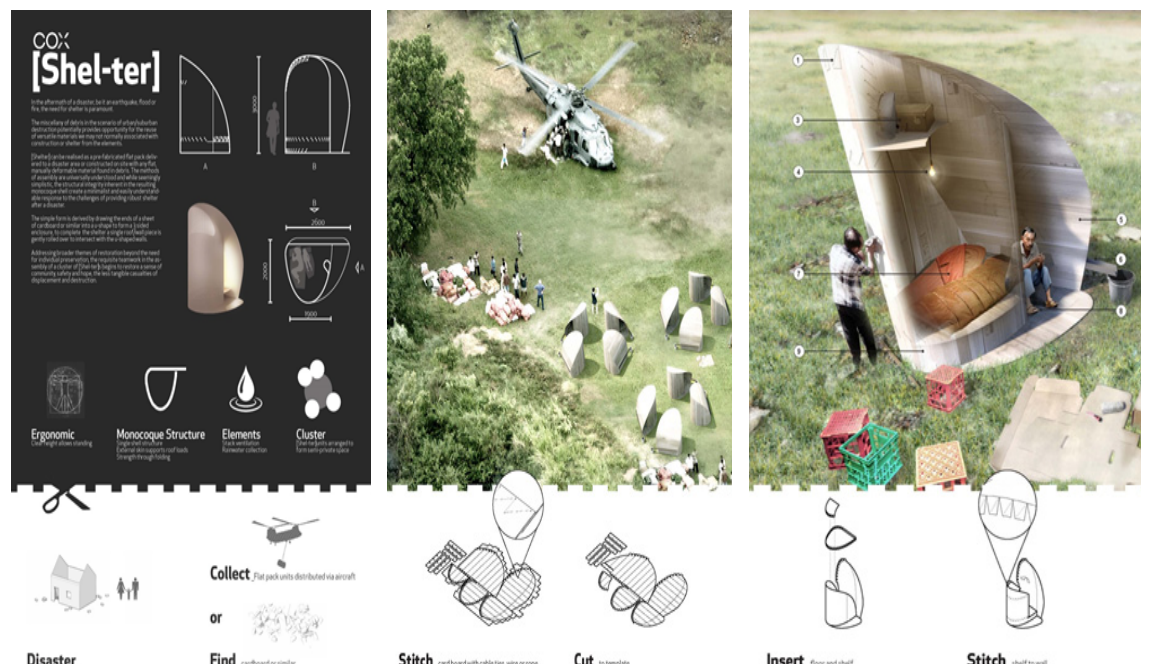

Figure 6: COX shelter. 


\subsection{Red Dot Design Award}

The Red Dot Design Award is an annual international design prize awarded since 1955. There are three prize categories for product design, communication design, and design concepts. Apart from categories there are no themes and conditions. Red Dot Design Award for emergency shelter deserves to analyze because it complements the other cases concentrated in functional aspects. Rather than suggested for common objective with specific subject, it offers different esthetical perspectives with author's free design will.

Felix Stark's 'Sphere emergency shelter' awarded in 2008 shows not only supplying shelter from extreme weather conditions but also reestablishing the feeling of security and companionship without loss of privacy. Nineteen units of tents offer room for three persons at a time, however, partition walls can be unbuttoned in order to create smaller or bigger sections for families, wards or similar. The center of Sphere is constructed as a social place, which consists of single families and inhabitants [5].

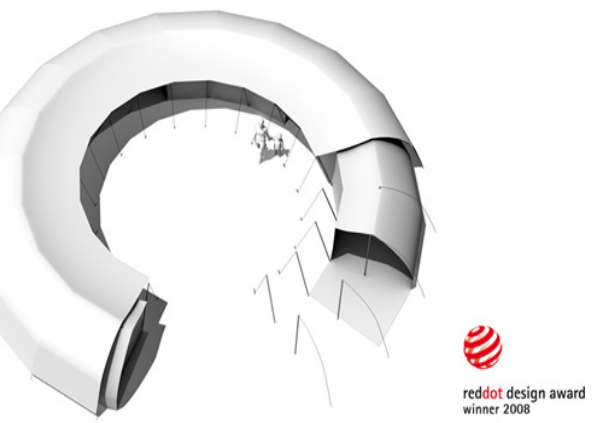

Figure 7: Simulation image of Felix Stark's 'Sphere emergency shelter'.

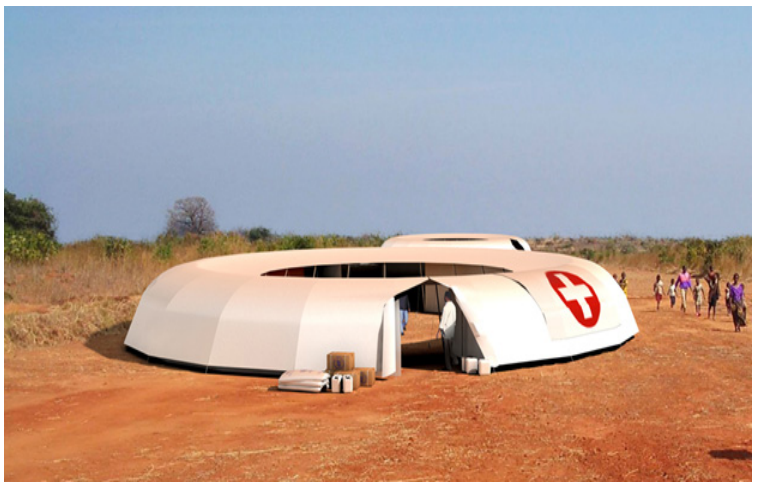

Figure 8: Installed 'Sphere emergency shelter'. 


\section{Deduced issues}

After the analysis of three cases for disaster shelters - Shelter Competition by John Brown University, Emergency shelter exhibition and Red Dot Design Award - we arranged eight major issues through the panel survey as requirements by demander on the one hand, and responses by proposer on the other. By adding the analysis of different kinds, the issues will be used for setting up architectural programs and guidelines of multi-purpose shelter.

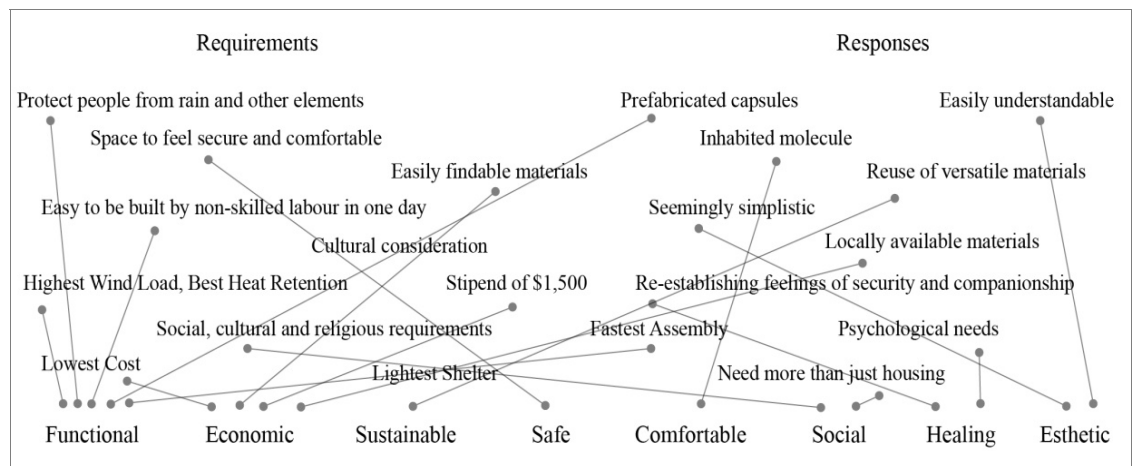

Figure 9: Keyword analysis of requirements and responses.

\subsection{Functional}

Most referred notions in analysis of disaster shelters were their 'functional' purpose. The disaster shelter not only has to provide a secure environment from extremely painful conditions in response to natural disasters such as a flood or earthquake, but also easy to be built by non-skilled labor. While 'Protect people from rain and other elements', 'highest wind load' and 'best heat retention' were required, 'prefabricated capsules' was suggested as a response.

\subsection{Economic}

Economic aspect of requirements is also abundant. Lowest costs, cost-effective, even stipend of $\$ 1,500$ were the required conditions. And what's more, the teams for 'Shelter Competition' must submit documentation to verify the cost of materials used in the shelter. The panel classified 'easily findable materials' as economic criteria rather than functional and sustainable because they insisted its economic value was more important.

\subsection{Sustainable}

As the sustainable design is often employed in response to global environmental crises, though not visible the sustainable requirements in three cases of analyses, the sustainability of materials seems like important considering the disastrous 
situations where the shelters are easily built and demolished. The sustainability will be treated from the perspective of reuse of shelters as it stands and the environment-friendly disposal after breakup. 'Reuse of versatile materials' was proposed for the 'Emergency Shelter Exhibition'.

\subsection{Safe}

The notion of 'Safe' is rather than functional whether the structure of shelter is safe or not, but safe from crime environment or psychological safety. Because of precarious situation the crimes and delinquencies are frequent. Crime might increase tenfold and many would become desperate and attempt to take it from others [6]. For that reason, the 'space to feel secure' was given as requirement.

\subsection{Comfortable}

Even if the notion of being comfortable was not demanded in the case of analysis, the habitability shows up in the proposal. The comfortability would be rated 'functional' if keeping ergonomic viewpoint, but it would be associated with 'comfortable' if we emphasis psychological side. Assuming the importance of human oriented space, the further studies would be taken for making planning criteria. LAVA's 'Digital Origami' presents well the comfortability with 'inhabited molecule'.

\subsection{Social}

Shelter's social, cultural and religious requirements were demanded being need more than housing. It should provide dignified accommodation for a family, with adequate flexibility to respond to social, cultural and religious requirements (e.g. the use of spaces by different genders and ages). It should take into account potential cultural considerations or sensitivities. 'Sphere emergency shelter' by Felix Stark would be representative example taking into account its social and psychological importance.

\subsection{Healing}

It would be progressive if we study the psychotherapy effect of shelter. The shelter could provide a space of healing in a disastrous environment, which is fundamental to the recovery process. In recent years, design for health care environments has begun to include aesthetic enhancements in an attempt to reduce stress and anxiety, increase patient satisfaction, and promote health and healing [7]. The specific conditions and environments of shelter would be suggested for being healing.

\subsection{Aesthetic}

We categorized 'easily understandable' and 'seemingly simplistic' as aesthetic rather than functional. Identifying in Felix Stark's 'Sphere emergency shelter' presented for the 'Red Dot Design Award', images and emotions from form are 
connected with human esthetic instincts. The aesthetic feature will be important if we take the multi-purpose shelter into account, and the cognitive effect of shelters should be studied later.

\section{Conclusion}

Initiated to draw the necessary issues required for drafting the architectural guidelines and programs for constructing multipurpose shelters, this study analyzed several cases of disaster shelters to survey the perspectives of the requiring party and the proposing party. We analyzed three different types of disaster shelters, and categorized them into eight issues. In conclusion, this paper selects the following as the essential factors of disaster shelters: functional, economic, sustainable, safe, comfortable, social, healing, and aesthetic.

Additional analyses should be complemented to generalize the planning criteria for multi-purpose shelter. Because the case analyses were limited to disaster shelters, the other cases (e.g. environmental art and artistic presentation) should be taken into account. Even the shelters in transportable environments [8] are our concern.

\section{References}

[1] http://www.jbu.edu/shelter_contest

[2] http://emergencyshelteraustralia.com/indexS-P.html

[3] http://1-a-v-a.net/projects/digital-origami-emergency-shelter/

[4] http://www.coxarchitecture.com.au/

[5] http://www.formstark.com/

[6] Thomas Stowe, The Guide To Living, Volume 1: Urban, Rural and Bush Living, Emergency Preparedness and Survival, lulu, 2011.

[7] Marc Schweitzer, Laura Gilpin, and Susan Frampton, Healing Spaces: Elements of Environmental Design That Make an Impact on Health, The Journal of Alternative and Complementary Medicine, October 2004, Vol. 10, No. supplement 1, pp. 71-83.

[8] Robert Kronenburg, Transportable Environments 2, Spon Press, 2003. 